\title{
Experiences of Deep Ecological Thinking in African Traditional Environmental Thought: A Philosophical Reflection in Perspective
}

\author{
Mulata Hiluf Abrha \\ Lecturer in the department of philosophy, Mekelle University, Ethiopia
}

\begin{abstract}
The logic of relational view as an ethic of maintaining balance of interaction between human beings and the rest of nature is central to both deep ecological worldview and African traditional environmental knowledge. It is argued in this article that relational view is an overseen/unrecognized depiction of resemblance between African Traditional Environmental Knowledge and deep ecological thinking first and for most in terms of the way they approach 'ontology of live and let others live.' Hence, their similarity in this respect rests on the fact that both affirms the inevitable logic of relations between humans and non-humans from which important scholarships would be drawn and exchanged with practitioners in the field of environmental ethics. Owing to this, the founder of Deep Ecology (DE) Arne Naess considers indigenous knowledge (with particular emphasis to the Eastern, Asian ethical tradition) as fundamental premises for any enlightened environmental thinking. Contrary to this deep ecological claim within indigenous knowledge, I argue that, very little or probably no attention is given to the similar contribution of ATEK to an ecologically friendly system of thought such as deep ecology in particular and to the whole spectrum of environmental ethics in general. Hence, this article aims at examining elements of deep ecological thinking in ATEK with particular focus on relational view (nature-relatedness). This article is also guided by Bryan Norton's Convergence Hypothesis theory (CHT) and concludes that ATEKs have attributes that can be seen as enlightened part of environmental ethics as has been done to the Asian, Australian, Red Indian traditional environmental thoughts.
\end{abstract}

Keywords: African, Traditional, Environment, Knowledge, Deep Ecology, Convergence.

DOI: $10.7176 / \mathrm{JPCR} / 45-01$

Publication date:October $31^{\text {st }} 2019$

\section{Introduction}

Environmental ethical imperatives are, often times, universal both in terms of content and concern. One among such concerns of practical philosophy that deals with ethical values attributed to the wellbeing, exploitation, climate change and generally wise use of things in the natural environment is referred to us environmental ethics. Multiple positions on how to approach values and practices of the natural environment have been developed ever since environmental ethics became a subject of academic discourse. Traditional African environmental thought is a recently added alternatives view into environmental ethics despite its old age (equivalent to distant ancestors in different parts of Africa). Deep ecology on the other hand was introduced half a century ago and it is richer in literature and more common in academic discussions. The term deep ecology was coined by a Norwegian philosopher Arne Naess and it has joined the domain of such values (lists) as an alternative way of looking at different values towards the rest of nature other than human beings since early 1970s and brought tremendous influences in countries such as Norway and Sweden. For Naess Deep Ecology refers to in depth understanding and re-examination of the long existing human-nature relationship followed by how and why questions in response to many counter threat of ecological crises. Thus, similar understanding of Deep Ecology is maintained in this article. Only for the purpose of this study, the terms environment and ecology are used interchangeably. The same holds true for the words traditional and indigenous because it is common to see that sort of synonymous in most literatures on African environmental thought except for slight contextual differences.

Originally, as environmental movement with multidisciplinary concern, Deep Ecology considers traditional insights as one of its ultimate premises for environmentally friendly worldviews. As a result, it is common to see convergence of principles accepted by Deep Ecology with many traditional approaches towards the natural environment. Hence, this article focuses on many points of convergence between traditional African environmental values as nature-relatedness and the relational values of deep ecological thinking. It examines experiences of relational approaches (deep ecological thinking) in African traditional thoughts.

Many assume that traditional African environmental view is the byproduct of the normative African communitarian Ethos in which case the latter boldly appreciates harmonious co-existence with others, not only humans but other part of nature too. Put differently, it is the traditional knowledge of people in Africa and recently attracting the attention of practitioners in the field of environmental studies to make sure if such African communal ethos has an inherent attributes of extending its ethical values into the rest of nature other than human being. 
This article also aims at exploring how deep ecological thinking manifests in the African traditional environmental values and look at the points of convergence with relational view of deep ecology. To that end I shall use Bryan Norton's convergence Hypothesis theory to examine common attributes of African traditional knowledge and deep ecological thinking. Norton considers deep ecology as enlightened environmental thought for the basic reason that the latter challenges the exploitative approach towards the natural environment. I argue in this article that Norton's environmental view also holds true for African traditional environmental thoughts because it doesn't rule out the non-existence of inevitable human interference in the natural environment and by the very fact of that and other evidence provided in this article, the African traditional environmental view qualify as one of the ultimate value of deep ecological thinking, particularly relational value theory and practice embedded in both. The logic of relationality as fundamental view of Deep Ecology and cultural value as well as ontological reality of African environmental ethics earnestly appreciates co-habituation of all natural things within the ecosystem as far as the essence of the relationship is meant for the common good and wellbeing of the agents involved. As a result, Deep Ecology challenges some disguised hegemonic postures in the Western anthropocentric traditions because as many environmental ethicists would have admitted, positions such as the latter are the cause of most distorted relationships between humans and the rest of nature.

\section{Background: Traditional Environmental Knowledge}

Challenging as it sounds; coming up with a single definition of indigenous environmental (IEK) knowledge with certain level of precision has never been an easy task for philosophers, anthropologists and scholars alike (Hunwick, A., \& Boye, J. 2008), (Hopper, C. Ed., 2002), (Stevenson, M.G. 1998). What is so common to all attempted definitions, however, is that Indigenous Environmental Knowledge is local knowledge set by a specific community and manifested directly or indirectly in the culture, belief, Art, ritual ceremonies, creativity and practices etc... of that particular community (Wiredu, K. 2004), (Workineh, K. 2005), (Langdon, J. (ed.). 2009). Indeed, the diverse nature of IEK is an old reason for the difficulty of setting out a universal definition that captures all elements within that multiplicity. "Traditional environmental knowledge is something that is learned during a lifetime and realizes the interconnectedness of the trees, soil and water" (Hiebert and Van Rees, 1998:3)

From an ecological vantage point, traditional knowledge represents experiences acquired over thousands of years of direct human contact with the environment (Julian T. Inglis, 1993). In some part of the world, like India and China, the growth of literature and level of investigation on indigenous people and their traditional is adding values to the existence, preservation of contents and practices of various traditional insights (Menzies, 2006; Lloyd N. Binder and Bruce Hanbidge 1993). The perception, attitude, approaches of preserving and ways of practicing traditional environmental values differs from country to country or continent to continent. As available literatures imply, the depth of research and level of utility of in the advanced world seems promising than in other cultures, (UNESCO and World bank documents, 1999-2016). Apparently, the status, progress and treatment of indigenous environmental knowledge in developing countries such as Africa are under investigated.

However, after a wide range of indifference and neglect, "academics, scientific researchers and others have 'discovered' that the knowledge which indigenous people hold of the earth, its ecosystems, the wildlife, fisheries, forests and other integrated living systems is extensive and extremely accurate", (Robert W. 1993:10). Incorporating IEK into the epistemic infrastructure of science and technology has been a rare and recent phenomenon since the dawn of modernity in the west (Usher P.J. 2000). Despite its apparent importance for science, economics, technology transfer and so forth, one way or another, IEKs have been ignored for a longtime and agents have tried to put IEK in the marginal scene of superstition ((Brockman, 1997), Gloria Emeagwali and George J. Sefa 2014), Richard Pankhurst, 2000).

In response, scholars in Africans, for instance Emeagwali, George J Sefa Dei, suggests that, 'academic scholarship has a duty to recognize these local cultural perceptive as legitimate sources of knowledge for a number of reasons; foremost, to recognize African peoples as producers and creators of knowledge' (Emeagwali and Dei, 2014:115). For them, there still are many unrevealing truths about the fact that "Africans have not been merely consumers of knowledge and added on, 'Ancient African civilizations bore sophisticated knowledge systems deeply embedded in local culture and social politic...' and put accounts of Ethiopian architecture, art and rituals in relation to the African IK and level proximity to modern science. Since ascertaining this line of thought in light of the whole spectrum of African indigenous thought is too much to handle in this piece, I shall first focus on environmental traditional knowledge and its basic premises for deep ecological thinking in Africa by taking some converging contexts in to account to indicate and discuss the criterion (precondition) of convergence.

Since the relationality theory of deep ecology boldly appeals to the importance of diverse environmental cultural insights around the world, discussion on the cultural values of the deep ecology further reveals more common concerns with African traditional environmental ethics. The founder of deep ecology Arne Naess (1982) extend his view of deep ecology in to other culture of the world such as Africa, South America and some part of 
Asia. He further moves on to mention examples of the Masi people of Kenya. The Msai are not disturbed by the vast populations of spectacular animals on their lands, and animals live with Msai people with notable coexistence. Such instances are proven example how some basic concepts of deep ecology support and are related to the rituals of many cultures outside of the west, as deep ecologist Dolores LaChapelle states it 'the role that ritual plays among traditional peoples is essential, in that it connects us to each other and to the nonhuman world with "the whole of our being' (G. Sessions, 1995: 18).

\subsection{African Traditional Environmental Knowledge as Nature-relatedness (ATEK)}

Though academic discourse on whether or not Normative African ethics has value extension into the rest of nature is still rare, experiences of deep ecological thinking in ATEK makes it easier to further deal with that claim. Dana-Abasi Ibanga, for example, argues current African environmental Ethics is essentially a portion and logical extension of the traditional normative African communitarian ethics (Ibanga, 2016). Assertions of this kind about African traditional environmental knowledge as ontologically inferred way of ecological thinking and also asserted in Segu Ogungbemi (1994) Ethics of nature-relatedness has been overseen by western environmentalists though the latter dwell in same logic of relationality between humans and the rest of nature. The notion of nature-relatedness ethics in this regard confirms the co-habituation of human being with rest of nature such as animals, trees, animate and inanimate things that exist in the ecosystem. Ibanga also argue the relational nature of ATEK based on the African egalitarian ethics of live and let live, another point where ATEK and deep ecology converge. Though it is problematic not to note the various contexts where different views might be needed upon careful examination of these system of thought, including original motives, economic and ecological goals, nonetheless, relational-ism lays at the heart of both, which is why the question, why do deep ecologists seem to fail to depict this vivid mutuality between ATEK and relational view of deep ecology seems appropriate. In this regard, contemporary African thinkers are also making independent scholarly effort without pointing out similarities of any sort 'the main thrust of African environmental ethics is to understand the ontology of man within the context of an environment he shares with non-humans (including spirits) and reveal the relational order that (ought to) govern being-in-the-world.'

Much like other aspects of African discourses as John A. Grim (1989) sets out, African conception of the natural environment can be understood as pre-colonial, during colonial and postcolonial. But what is inherently common to all is that the traditional values (pre-colonial) and conceptions of African people towards nature in general is an extension of this communal ethical structure. To further increase the cogency and clarity of such continuum, a closer look at the content and claims of African Traditional environmental ethics from the precolonial vantage point is worth a consideration and the pre-colonial environmental conception of Africans is highly characterized with social, spiritual, psychological, super-human and intergenerational settings as Kwasi Wiredu has remarkably put;

the external world that the traditional African, as far as I know, recognizes and includes other human beings and living and non-living beings as well as extra-human beings of various grades of power and intelligence ranging from the super-human to the sub-human. All this are regarded as regular parts of the world order. There is no question of trying to control or dominate this whole scheme of things and beings (1994:45).

Since Wiredu's explanation and analysis of African traditional knowledge is from purely an African environmental perspective, it best represents to the human-nature interactions and relationships in the precolonial African society. Norms, respect and values to the natural environment was based on multitudes of cultural, cosmologic and spiritual viewpoints. It was a traditional ethic that reasonably accepts the existence and wellbeing of all natural things as equal and respected. That is way another well-known African philosopher Henry Odera Oruka (1994:vi) supports Wiredu's proposal for the global communities to reconsider the African traditional values of natural environment as cogent grounds to ecological moral consider-ability in the process of human-nature interaction.

Furthermore, Godfery B. Tangawa (2004) in his analysis of pre-colonial Africa tradition and the environment argues that the African ecological thought has characterized by ecological diversity within communality (Tangwa, 1996: 192). Healthy and harmonious human-nature relation has long been practiced in the pre-colonial African traditions. 'The precolonial traditional African metaphysical outlook can be described as eco-bio-communitarian' (ibd). According to Tangwa, this pre-colonial tradition of modest relation and peace full coexistence with nature is generally characterized by the egalitarian view of deep ecology. Similarly, according to Burnet and Kang'ethe's reference to Bantu culture in Kenyan highlands, Tangwa particularly mentioned the Nso' culture of grassy highlands of Bamenda in Cameroon as one of the primordial example of pre-colonial traditions of African people.

On the contrary, many writers admit that the Western perception about the pre-colonial African society has been very misleading and even offensive because the latter is being considered as devoid of logical cognition and metaphysical affinity to appreciate and preserve natural environment (Burnet and Kang'ethe, 1994). Burnet and Kang'ethe argue that as opposite to the popular misconception of the Western mind about primordial knowledge 
of the pre-colonial African people, there are many African indigenous cultures with deep and spectacular environmental consciousness. For instance, in their analysis of the Bantu culture in Kenya highlands, Burnet and Kang'ethe explore how the Bantu culture resists the Western instigated way of environmental preservation or wilderness in defense of their own traditionally established ecological framework. These writers also believe that there is a sort of fundamental clash between the indigenous and Western environmental ethics though the former precedes the latter both in depth and essence. According to them, the emerging African environmental ethics has to be designed in line with the pre-colonial traditional ethical structure of Bantu culture. The Bantu's sheer depth of believe in very existing thing as united and regulated part of the "force' has already signified an original early African environmental worldview proved by their mythical power of resistance for external western resistance. Burnet and WaKang'ethe concludes that the nature and extent of moral standing in one of the earliest African tradition; Bantu philosophy is an academic project that requires further investigation because they believe that will be a good starting place to examine and recognize the wilderness value embedded in the ATEK.

Some academies in Africa on the contrary regret about the misguided assumptions of pre-colonial African thought, the place of the latter during the colonial time was significantly discouraged and misunderstood. As Robert H. Nelson 2003:67) notes, the Western ethical orientation in African land is more interested in mystifying and belittling the aboriginal ecological traditions than empowering and rethinking the underlying substance of African traditional thought. 'The efforts of such African conservationists, however, have often been undermined by their European and American counterparts' (Hutton and Dickson, 2000:23). Western thinkers were so reluctant to have a room for the actual existence and relevance of pre-colonial environmental ethics. They showed no interest of any kind on the reality to satisfy themselves through the western-built myth and uncivilized perceptions of African traditional thought. Simply put, Nelson reflection suggests that despite the truth and existence of ecologically friendly cultures in different parts of Africa, the Westerns have remained very reluctant to accept what is really at stake and their mind is mockingly dominated by metaphorical association of the 'uncivilized' pre-colonial mind of African people. Such projects of devaluing the African indigenous environmental consciousness have been taken place let alone during the colonial time but even in the postcolonial Africa.

As part of the project of reassuring the real existence of ATEK by the African scholars, Professor Workineh Kelbessa, in his study of African Indigenous Environmental Ethics, particularly of the Oromo culture in Ethiopia states that there are remarkably uninvestigated indigenous traditions in different parts of Africa that can be taken as essential body of global environmental wisdom. The idea of Saffuu in Oromo indigenous environmental knowledge, for instance is a moral instruction that moves relationships among natural things as healthy and appropriate as possible. It restricts the extent and manner of human intervention in the natural environment. He asserts 'Saffuu regulates the relationship between various animals and human beings. The Oromo moral code does not allow irresponsible and unlimited exploitation of resource' (Workineh, 2005:9).

Many scholars who have made rigorous studies in areas of indigenous environmental ethics apparently failed to make important implication about the global significance of African ecological thoughts (Workineh, 2005). This is partly because of the misconceived view that Africans can't comprehend meaningful environmental consciousness and therefore are not capable of proper value assignment in the natural environment. Concerning the African environmental condition of colonial period and the place of indigenous knowledge, Workineh further underscores the manner of Western policy imposition up on African land was very random from the outset beginning from the late nineteenth and early twentieth because they didn't seem to care about the pre-existing environmental/local conditions and traditions that resulted in apparently contrasting intent with the real, even vital interests of African people (Workineh, 2009)

The condition of ATEK in the postcolonial Africa therefore is not far different from the colonial time because the legacy of the latter is still unraveled followed by the expansion of Western anthropocentric humanism in the entire continent. Though attempts are made by African farmers and pastoralists to reaffirm ATEK by abandoning the Western setting of environmental management after the end of colonialism, the dominant part of African conservation policies and system of ecological governance still remains Western in postcolonial time (ibd). Of course, an unreserved scholastic effort of a few African professional environmental ethicists as a challenge to the Western anthropocentrism has begun to emerge. I think one of the main tasks of these scholars as highlighted earlier is to re-examine traditional African thoughts and practices as a solution to the already existing and forthcoming environmental problems of African land, which are mostly caused by neocolonial environmental trend and economic development as a globalized agenda. In simple terms, the value and significance of indigenous environmental thought in Africa don't vary over time, from pre-colonialism to postcolonial times. What has been changing about them, in my understanding, is people's attitude towards them both in and out of Africa. For instance, there was a wrong conviction in the minds of colonized people who had indoctrinated by Western anthropocentrism to make them believe that their own tradition is environmentally unfriendly for the simple fake reason that it is said to be "uncivilized" by foreigners. Moreover, it is beyond a simple guessing to think that there was tremendous pressure from the colonizers for those Africans who had 
believed otherwise during and after the colonization process. Thus, what was directly or tacitly happening in the process of colonization regarding the environmental values of African traditions has devastating impact on the present trend of ATEK. For instance, an increasing reliance on the Western anthropocentric approach for natural resources management and wilderness preservation instead of rethinking about ATEK as an alternative way out from the growing environmental problems. Vimbai C. Kwashirai (1993) argues that, 'A key feature of African environmental historiography lies in its emphasis on colonial capitalism and imperialism as environmental contexts and processes. African environmental history has been dominated by analyses of the colonial experience and its legacies. The colonial state has also been characteristically prominent in these works.

Further, another reason for an increasing disregard of traditional African ethics of the environment on the one hand and the rapid domination of Western anthropocentrism on the other end is because of some absurdly wrong conclusions reached by colonizers in the colonial time even before and one of these generalizations is that Africans cannot have meaningful share in the global environmental ethics because they are practically in capable of doing so and if they do, it must be technically and conceptually defective. Hence, I can say that such erroneously pursued hasty conclusions and misconceptions about the African people and their traditional ecological consciousness is mostly, if not entirely, taken place in the colonial time. These and other similar assumptions without any significant critical study of the African traditions knowledge have led to misleading judgments and misinterpretations as Workineh suggests,

Some will object that, empirically, Africa has one of the worst environmental records on Earth, and therefore obviously can't be expected to contribute very much to global environmental management. Africans, it will be said, with all solemn objectivity and honesty, clearly are incapable of overcoming their own environmental and development crisis. To many, this seems a plausible assessment of the African environmental record. But the real issue is not so simple. One has to examine how and why Africa has faced an environmental and development crisis before concluding that Africans are environmentally unfriendly. (2009:10)

From the post-colonial vantage point and having both the African traditional ecological knowledge (ATEK) and its Western dominant counterpart in mind, we have to be clear on one thing, is it the former that fails to suit the latter or vice versa? Logically, when it comes to the issue of compatibility, one can claim that, they both must not be a perfect attendant to each other because the real condition of environmental controversy in African never implies such things. Indeed, regardless of its depth and intensity, both have certain weakness when compatibility and being a companion is weighed up in light of genuine environmental ethics.

Back to the exploration of Deep Ecological experiences in ATEK, it is easily recognizable that the place of nature within the human world in Africa traditional environmental thought is hard to compromise. Reconceptualizing discourses underpinned most ethicists imply the fact that similar to the Eastern environmental traditions, African ecological thoughts promote relationalilty, co-existence and interconnections between humans and nonhuman beings as well. Since ATEK are deeply intertwined with moral, spiritual and social life of the people, then, they can be counted as sound basis of alternative environmental ethics together with DE and Norton's convergence hypothesis. One likely scenario that inspires deep ecologists and the supporters of ATEK is the truth that they both dwell in the deepest level of spiritual and ontological phenomena and admit the vitality or inevitability of human and nonhuman relationship. Besides, they both agree that Western anthropocentrism has been and still is the biggest cause of environmental problems and threatens the balance of global natural ecosystem. They also believe in and accept the intrinsic value of nature with minimal exceptions, reasonable interference without excessive exploitation which turn implies they both appeal to Norton's idea of weak anthropocentrism. But these all does not mean that there is no difference between the two in terms of depth, structure, historical emergence and development which are not the intention and subject of detailed discussion in this article.

\subsection{Convergence between ATEK and Deep Ecological Thinking.}

As pointed out earlier, closer examination of ATEK would probably lead scholars in the field of deep ecology to consider African indigenous knowledge as part basic values because the logic of inevitable relations and unshakable interdependence among things in the natural environment are central to both. For this claim to be proved true and accepted, it is worth referring to have a look at many common elements of ATEK in the Eight point platform and Deep Ecological Apron Diagram (also see appendixes). Besides, indigenous knowledge according to Naess and Sessions is believed to be a specified derivational effect of the ultimate norms including culture, philosophy and religion as indicated in the apron diagram (see appendix1). But given the broadness and multiplicity of these general premises, we can't expect too much compatibility or similarity in the next (level two) because there are some apparent diverging tendencies and ambiguities within and many critiques of Deep ecology as articulated by Naess begins at level two due to generalizations and vague ethical imperatives. For example, thinking the extent of intrinsic value in the first principle, one may object, is impossible to apply the full sense of it without considering some instrumental values of human being. The same assertion and objection holds true to principle two that strictly recommends non-interference. What about people's right to get an access 
to natural resources to fulfill daily subsistence? Thus, such inconsistences in the universal application of the eight principles of DE may invite some imperative conditions to adopt Norton's weak anthropocentrism to make them fit the context of present and future African environmental ethics.

It has to be noted that another point of convergence between relational view of DE and ATEK is that there are important elements and implications that are worth considering to Third World countries including Africa and vice versa. Naess, in his 1991 article, The Third World, Wilderness and Deep Ecology, states that there is a growing alliance between environmental conservations in the Third World and DE. He also suggests that since people in the Third world are struggling to reduce poverty, the sort of cooperation should stand on two basic conditions. One, it should be in line with the project of reducing poverty in the Third World. And secondly, it should be free from any kind of intention to save nature on the expense of people in there. Naess's discussion of DE and the condition of the Third World is held in reference to much non-Western indigenous knowledge in some part of Europe, Asia and Africa. For example he mentions the Masi people in Eastern Africa, Kenya and Tanzania and their environmentally friendly traditions. Moreover, these people have started working with some supporters of DE though Naess doesn't make it clear about the nature and intent of such cooperation. He has astonished by the notable ecological harmony he saw in Msai people. "What holds true for the Msai holds as well for a great number of other peoples and cultures in the Third World. Ecologically sustainable development may proceed in direct continuity with their traditional culture as long as population pressure remains moderate (Naess, 1991:406). From Naess' perspective, there is possibility to draw lessons from the Msai culture for environmental consciousness of the global Third World countries.

In fact, few African environmentalists and writers have also reflected similar views with the basic assumptions of DE as relationality. For instance, P.A. Ojomo (2001) in his article Environmental Ethics: An African Understating; best explained the core value of relationality in African traditional thought as, "To harm nature is to harm ourselves and to defend earth is self-defense" (2011:573). He also points out that there are two basic tenets in DE, first, all natural things in the ecosystem as interrelated whole have equal ontological privilege, secondly and closely related to this is all things in the ecosystem as individual entities are free to flourish and reach what Naess calls the stage of self-realization. As far as the likelihood of relational view of DE and ATEK is concerned, Workineh in his study of African indigenous environmental ethics, particularly Oromo culture in Ethiopia also stated that, "[t]hose who destroy their land and resources destroy themselves, because their survival depends on the life of their land" (2005: 24). Indeed, one may object, is there any relevant relation between DE and AEE? My answer for this question would be very positive.

For instance, the above cited statements by Ojomo and Workineh, they are typically characterized as relational views. Workineh further insists that there are remarkably uninvestigated indigenous traditions in different parts of Africa that can be taken as essential body of global environmental wisdom. He also stressed that there is an urgent need for revitalizing indigenous ecological knowledge in Africa and hence, enough attention should be given for the purpose of inspecting vital environmental knowledge within these traditions. According to him, the Oromo culture in Ethiopia has many ecologically conscious principles that service as material and spiritual guidelines in the process of human-nature interaction. For example, the idea of Saffuu in Oromo TEK is a moral guideline that moves relationships between/among natural things as healthy and appropriate as possible. The principle of Saffuu also puts restrictions on the extent and manner of human intervention in the environment. Workineh states,

Saffuu regulates the relationship between various animals and human beings. The Oromo moral code does not allow irresponsible and unlimited exploitation of resources and human beings. In this case, then, it can be argued that the Oromo conception of saffuu is based on justice. It reflects a deep respect and balance between various things (2005:9) which is much similar to what Freya Mathews in her metaphysical analysis of DE concludes, "Reality is thus viewed as fundamentally relational (ecological), rather than aggregative, in its structure. To this metaphysics of interrelatedness is then added an ethic of interrelatedness according to which all forms of life are equally entitled to live and blossom" (Mathews, 2001:218). Simon Bradshaw also states sort of endorsement to Næss's 'relational, total-field image', in which the identities of organisms, including humans, are defined in terms of their ecological relations to each other.

I would also like to mention another ecologically friendly practice in Raya Azebo of Northern Ethiopia (Southern Tigray) in terms of their culture of respecting to animals; who literally swear in the name of Cattles.

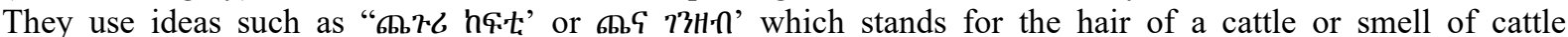
receptively, which implies telling the final truth nothing less. They are Semi-pastoralists. Their life is significantly connected to domestic animals, basically cattles and camels. Besides, in an area where I have grown up nearby Raya Azebo, all animals living around Church forests are highly protected because the people think that they inhabit in God's home for their safety. Hence, for most spiritually informed adult, it is highly forbidden to kill or harm animals in any way if they dwell around church areas. But, the society in question lacks consciousness on the proper treatment of wild animals outside the church. They have more or less aggressive relationship with rest of nature. 
The bottom line is that there is an apparent resemblance between African indigenous ecological insight or ATEK and DE as relationality. As mentioned before, Naess considers spirituality and other environmentally friendly traditions as eco-philosophies and decisive backgrounds to build further environmental principles and policies. Hence, I argue that, as opposed to the mainstream environmental ethics, African indigenous environmentalism, which is highly embedded in the local community's primordial knowledge, has to be considered as good reference for environmental policy formation in Africa as suggested by some African environmentalists.( Wiredu,1994, Tangwa, 2004, Workineh,2000, 2005, and Ojomo, 2011) . But, to do so, it needs reversing the top down trend, which is the Western oriented role of African government officials who mostly manage natural resources without the consent and knowledge of African people; into bottom up approach that rationally counts the values and principles of indigenous people dwelling in that actual environment. In line with such reconfiguration, it sounds very advisable if they (the officials) examine how like-minded environmental policies and other ecological approaches with socio-economic realities and contexts of the African people. Ojomo (2011) for instance suggests three fold policy frameworks regarding African view of environmental ethics. The first one is educational. Courses in environmental ethics should be included and properly given to increasing consciousness about human-nature relationship and sustainability. The second one is legal. Some imperative legal compulsion has to be formulated regarding environmental impact assessment (EIA) before business sectors are already invested. The last one is technological. He claims that only environmentally friendly technologies should be encouraged in Africa. He said, unchecked "Western technologies can be deemed guilty until proven innocent" (Ojomo, 2011:577). In addition to what Ojomo suggests, the fact that the ATEK is practically combination of both anthropocentric and ecocentric in its intent, Norton's contextual hypothesis based on the SMS criterion seems empirically compatible in order to bring together preservation and conservation agendas.

\subsubsection{Bryan Norton's Convergence Hypothesis.}

According to Norton (1989) there are three essential principles that he proposes as bench marks of convergence for all environmental worldviews and I argue there are important points of reference to show how relationality reveals itself in both deep ecology and ATEK. (i) Common denominator objective, (ii) Bearable economic and ecological cost. (iii) 'Safe Minimum Standard (SMS)' (Norton, 1989). Norton's main argument is that, there is a growing sense of collaboration and working together among environmentalists (for instance deep ecology with weak-anthropocentrism) because they cannot deny the fact that there is a "common-denominator objective regardless of their temporal varying ecological value commitment" (Norton,1989:191). For him, goals and standards should be set in light of bearable economic and ecological cost, which he calls 'Safe Minimum Standard (SMS)' (1989).

He claims that if they have the real motive that originates from practical interest to preserve nature and maintain healthy relation between human beings and the rest of nature, their goals won't ultimately diverge.

The contemporary African environmental ethics as byproduct of normative African communitarianism shares many principles of deep ecology and vice versa. Since this article partially aims at establishing experience of ecological scholarship between African traditional environmental thought and deep ecological thinking (basically its relationality part), then it appears important to examine the nature of ecological common ground where both converges for the similar values. To this end, I find Norton's Convergence Hypothesis important. Norton proposes some bench marks through which all environmental concerns and theories share in common for cogent ecological and human values that lay at the heart of environmentalism. Norton's main argument is that, there is a growing sense of collaboration and working together among environmentalists because they cannot deny the fact that there is a "common-denominator objective regardless of their temporal varying ecological value commitment" (Norton,1989:191). What does Norton mean by this? It means that despite the varieties of ideological and theoretical antagonism among various environmental ethical theorists, it has to be noted there are undeniable values that has been surfacing as core values of all environmental positions; namely, the mutual wellbeing and survival of both human and non-human entities. The common denominator objective in this context implies the ultimate priority that all environmentalists are convincing themselves to accept without preconditions. I argue that that common ground objective that all environmentalists would like to consider is the logic of relationality which is common to both in the theory of deep ecology and the African traditional environmental thought.

Norton also raises another very important point; i.e the notion of 'economically and ecologically bearable cost'; which I argue is applicable to both deep ecology and African traditional environmental thought. The former as discussed in the previous sections affirms the necessity of human reasonable interference in the natural environment. But that interference when evaluated within the matrix of convergence of human material need versus ecological wellbeing, it is sanctioned by affordability state of affairs or preconditions because limits on how and when a given community of human should be allowed to enjoy the fruits of nature (resource) is theoretically set out in the deep ecological worldview. Similarly, there is no free ride of exploiting nature or destroying nature or harming nature when it comes to the African traditional environmental thought because the 
latter is embedded in the egalitarian sense of existence "live and let other live" sort of normativity.

Furthermore, Norton proposes another point of convergence for all environmentalists to cooperate instead of diverting and widening superficial differences. He suggests that putting "Safe Minimum Standards (SMS) criteria would lead practitioners, policy makers and environmental academics into a consensus. This idea of imposing formal limits to the level and extent of exploitation of the natural environment actually includes to both the theory and practice of alternative environmental ethics such as deep ecology and cultures outside the west such as the African traditional ecological thought. A typical example for this seems the various treaties on Carbon emission. Be its practicality as it may, many argue that it is a good starting point in terms of delimiting the degree of exploitation and environmental degradation. It is not particularly given to a specific theory or culture practice of preserving nature. Rather it tries to figure out ways as how to satisfy human interest with reasonable resources (I mean wise use of natural resources) so as to accommodate both realities (mutual existence of human and non-human. I believe that, in the relational view of natural environment as it is already identified in African environment thought and deep ecology, attempts connect the two components and rationalize their relations instead of letting or forcing us to choose one and abandon the other because both are unavoidable state of affairs.

\section{Conclusion}

Similar to other academic domains, grand western ethical narratives assert time and again that most literary outputs are inclusive and universal. But academic flexibility to uphold traditional inputs from other cultures pretty rare and appears a recent development. Following that trend, attempt is made in this article to imply the fact that elements of ethical imperatives towards the natural environment has long been existed in the ATEK though it begs a question to claim that who takes what/when if some basic convergence exist. Since to argue that there are points where common treatment of the natural environment reflects doesn't necessarily entail problem of origin, there still is a chance to depict many environmentally friendly ideas for meaningful and rational practices of ethical imperatives as a values and concerns towards the natural environment.

Generally, discussions in this article focus on exploring common scholarships between African traditional environmental thought and the relatively popular environmental theory of deep ecology. One of the common elements that I have tried to defend and bring to the front scene of academic discussion is the idea of relationality that reveals the undeniable logic of mutual existence between human and non-human entities as vividly given in the fundamental values of both. Hence, their theoretical values and pragmatic relevance in the project of reducing ecological crisis would better strengthen if they are properly examined. Unlike the subject or main concern of other mainstream environmental ethics of the west, deep ecological thinking is recognition and appreciation of indigenous environmental ethics collectively known as non-Western cultures by virtue of this deep ecology can be taken as a potential companion to contemporary and future African environmental ethics since the foundation of the latter lays on long rooted cultural beliefs and rituals of the bigger umbrella of communitarianism.

\section{Reference}

Andre Lalonde. (1991). African indigenous knowledge and its relevance to environment and development activities. Bloomington Indiana. Indiana University Press.

Gezahegn Ayele.(2003). Indigenous Knowledge and Practices for Soil and Water Management in East Wollega, Ethiopia. Addis Ababa: Ethiopia.

Gloria Emeagwali and George J. Sefa Dei (eds.).(2017), African Indigenous Knowledge and the Disciplines. Canada: University of Toronto. Pp. 110-115.

Hernain Crespo-Toral et al (2000). Culture Counts Financing, Resources, and the Economics of Culture in Sustainable Development. UNESCO and World Bank.

Hiebert, D., and K. Van Rees (1998) Traditional Knowledge on Forestry Issues within the Prince Albert Grand Council. Prince Albert, SK.

Hobson, G. (1992). Traditional knowledge is Science. Northern Perspectives: Indigenous Peoples 'Restoration Network.

Hopper, C. (Ed.). (2002). Indigenous knowledge and the integration of knowledge systems. South Africa: New Africa Books.

J. T. Inglis (ed.). International Program on Traditional Ecological Knowledge and International Development Research Centre. Ottawa: Canada.

Julian T. Inglis,1993 (ed.) Traditional Ecological Knowledge: Concepts and Cases. International program on traditional ecological knowledge. Canadian Museum of nature.

Kelbessa, Workineh (2009) Africa, Sub-Sahara. In Callicott J. Baird and Frodeman, Robert (2009) Encyclopedia of Environmental Ethics. USA:MaCmillan Reference. Pp.10-18

Langdon, J. (Ed.). (2009). Indigenous knowledges, development and education. Rotterdam:Sense. 
Lloyd N. Binder and Bruce Hanbidge.(1993). Aboriginal People and Resource Co-Management. Western Arctic and Resource Co-Management under a Land Claims Settlement.

Naess, Arne (1985) The Deep Ecology "Eight Points" Revisited. In Sessions, George (ed.). Deep Ecology For The Twenty First Century. Boston and London Shamflala puplishing press..pp.213 222.

Naess, Arne (1991) Deep Ecology and Lifestyle. In Sessions, George (ed.). "Deep Ecology For The Twenty First Century.” Shamflala puplishing press. Boston and London.pp. 259-263.

Nelson H. Rebort.( 2001). Economics as Religion: from Samuelson to Chicago and Beyond. USA: pennsylvania state university press.

Norton, Bryan. (1991) Towards Unity Among Environmentalists. New York: Oxford University Press. Pp. $102,191$.

Ogungbemi, S. (1997). An African Perspective on the Environmental Crisis. In Louis P. Pojman (Ed.), Environmental Ethics: Readings in Theory and Application. Boston: Jones and Bartlett Publishers.

Ojomo, P. A .(2004). Environmental ethics: An African understanding. In Wiredu, Kwasi (ed.). A Companion to African philosophy. Oxford: Blackwell publishers. p.560-573.

Oruka, Odura H. (1994). Philosophy Humanity and Ecology; Philosophy of Nature and Environmental Ethics (eds.). Nairobi:The African Academy of Sciences press.

Robert Wavey Traditional Ecological Knowledge in Perspective. International Workshop on Indigenous Knowledge and Community-based Resource Management:

Shaw. (2008). Indigenous Knowledge Disaster Risk Reduction. Kyoto University .

Stevenson, M.G. 1998. Traditional knowledge and environmental management: from commodity to process. Paper for NAFA conference, Celebrating Partnerships. September 14-18, 1998. Prince Albert, SK

Stevenson, M.G. 1998. Traditional knowledge and environmental management: from commodity to process. Paper for NAFA conference, Celebrating Partnerships. 1998.

Tangwa, Godfery (2004) Some African Reflections on Biomedical and Environmental Ethics. In Wiredu, Kwasi (2004) (ed.). A Companion to African philosophy. Oxford: Blackwell publishers. Pp. 192.

Warren, D. (1991) Using indigenous knowledge in agricultural development. World Bank Discussion Paper 127. Washington, DC: World Bank.

Wiredu, K. (2004)( ed.). A Companion to African philosophy. Oxford: Blackwell publishers

Workineh, K. (2005) The Rehabilitation of Indigenous Environmental Ethics in Africa. London, Thousand Oaks, SAGE Publisher.

The Apron Diagram of Deep Ecology

\title{
APPENDIX A
}

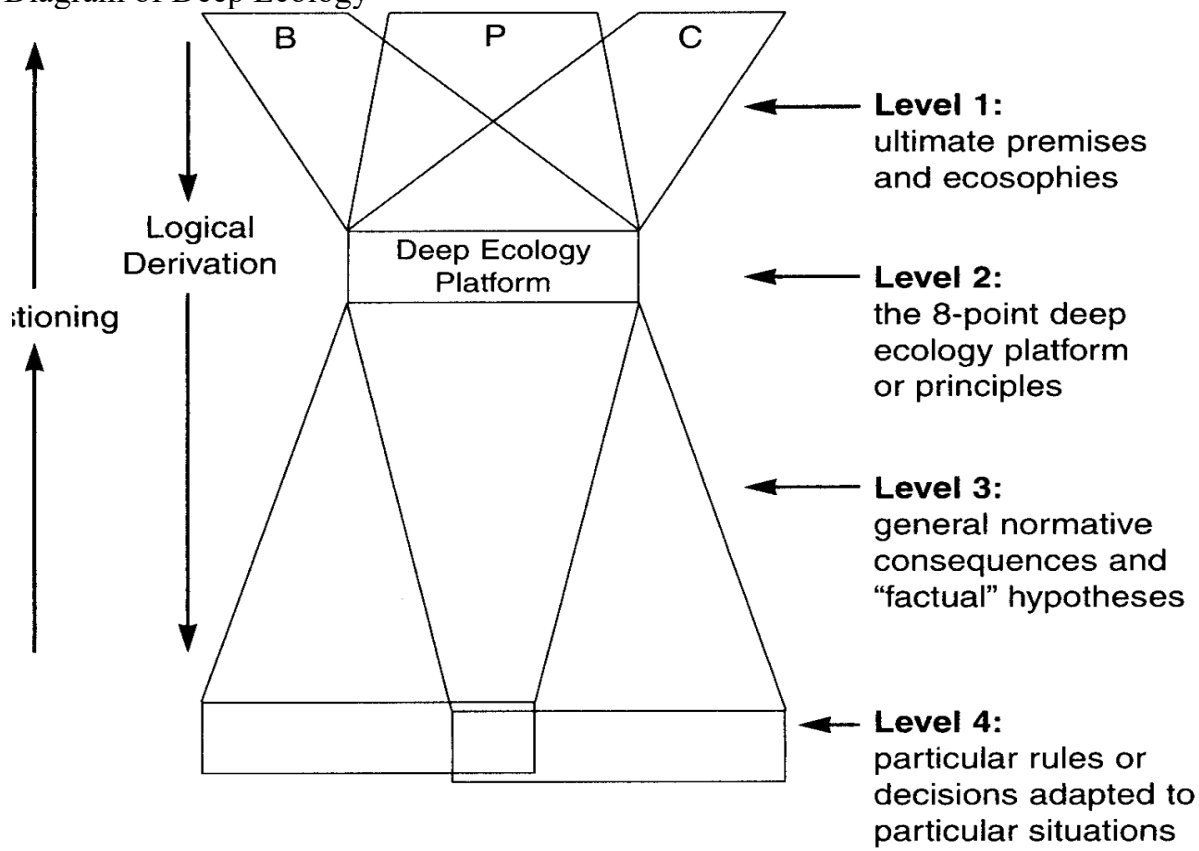

Examples of kinds of fundamental premises: particular situations

\author{
$\mathrm{B}=$ Buddhist \\ $\mathrm{C}=$ Christian \\ $\mathrm{P}=$ Philosophical (e.g., Spinozist or Whiteheadian)
}


Appendix B

\section{Table1: Experiences and convergences of ATEK with Deep Ecology in The Eight Platform Principles}

\begin{tabular}{|c|c|c|c|}
\hline no & Platform & $\begin{array}{l}\text { Common ground with } \\
\text { ATEK }\end{array}$ & Claimed Weakness \\
\hline 1 & $\begin{array}{l}\text { The flourishing of human and non-human life on } \\
\text { Earth has intrinsic value. The value of non-human } \\
\text { life forms is independent of the usefulness these } \\
\text { may have for narrow human purposes. }\end{array}$ & Intrinsic value nature & $\begin{array}{l}\text { Ignores the fact that } \\
\text { some elements of nature } \\
\text { may have utilitarian } \\
\text { value }\end{array}$ \\
\hline 2 & $\begin{array}{l}\text { Richness and diversity of life forms are values in } \\
\text { themselves and contribute to the flourishing of } \\
\text { human and non-human life on Earth. }\end{array}$ & $\begin{array}{l}\text { Interdependence } \\
\text { among natural things } \\
\text { including humans } \\
\text { (nature-relatedness) }\end{array}$ & $\begin{array}{l}\text { Contribution in this } \\
\text { context can be } \\
\text { interpreted } \\
\text { anthropocentrically. }\end{array}$ \\
\hline 3 & $\begin{array}{l}\text { Humans have no right to reduce this richness and } \\
\text { diversity except to } \\
\text { satisfy vital needs. }\end{array}$ & $\begin{array}{l}\text { Limited interference on } \\
\text { nature }\end{array}$ & $\begin{array}{l}\text { It ignores what non- } \\
\text { developing part of the } \\
\text { world demands }\end{array}$ \\
\hline 4 & $\begin{array}{l}\text { Present human interference with the non-human } \\
\text { world is excessive, } \\
\text { and the situation is rapidly worsening. }\end{array}$ & $\begin{array}{l}\text { Environmental ethics } \\
\text { against exploitation of } \\
\text { nature is common to all }\end{array}$ & $\begin{array}{l}\text { Category mistake of the } \\
\text { notion of interference }\end{array}$ \\
\hline 5 & $\begin{array}{l}\text { The flourishing of human life and cultures is } \\
\text { compatible with a substantial decrease of the } \\
\text { human population. The flourishing of non-human } \\
\text { life requires such a decrease. }\end{array}$ & No common ground & $\begin{array}{l}\text { Presenting human } \\
\text { depopulation as solution } \\
\text { is controversial one and } \\
\text { criticized. }\end{array}$ \\
\hline 6 & $\begin{array}{l}\text { Significant change of life conditions for the better } \\
\text { requires change in policies. These affect basic } \\
\text { economic, technological, and ideological structures. }\end{array}$ & $\begin{array}{l}\text { There is an integration } \\
\text { of policy with ATEK } \\
\text { recently }\end{array}$ & $\begin{array}{l}\text { Types and exceptions of } \\
\text { policies are not } \\
\text { presented }\end{array}$ \\
\hline 7 & $\begin{array}{l}\text { The ideological change is mainly that of } \\
\text { appreciating life quality (dwelling in situations of } \\
\text { intrinsic value) rather than adhering to a high } \\
\text { standard of living. }\end{array}$ & $\begin{array}{l}\text { Coexistence and } \\
\text { richness in life forms } \\
\text { appreciated }\end{array}$ & $\begin{array}{l}\text { Vagueness in feasibility } \\
\text { and limit in wealth or } \\
\text { material desire }\end{array}$ \\
\hline 8 & $\begin{array}{l}\text { It is imperative that adherence to these platforms } \\
\text { should be followed up and anyone failed to do has } \\
\text { to be held responsible }\end{array}$ & $\begin{array}{l}\text { Attainable } \\
\text { obligation }\end{array}$ & $\begin{array}{l}\text { Principles } \\
\text { generalized } \\
\text { exception }\end{array}$ \\
\hline
\end{tabular}

